\title{
XXXII. Reply to Mr. Henderson's Remarks on Captain Sabine's Pendulum observations
}

\section{Capt. Edward Sabine R.A. F.R.S.}

To cite this article: Capt. Edward Sabine R.A. F.R.S. (1827) XXXII. Reply to Mr. Henderson's Remarks on Captain Sabine's Pendulum observations, Philosophical Magazine Series 2, 2:9, 176-177, DOI: $10.1080 / 14786442708675642$

To link to this article: http://dx.doi.org/10.1080/14786442708675642

里 Published online: 10 Jul 2009.

Submit your article to this journal $[\pi$

Џll Article views: 2

Q View related articles $₫$ 


\section{Capt. Sabine's Reply to Mr. Henderson's Remarks.}

quantity of fresh-water limestone or travertine on the side of Civita Vecchia. It is first seen constituting large platforms pear Mala Grotta and Guido; it then ceases : but after having passed the Pulidoro and the hamlet of the same name, considorable masses of fresh-water limestone are traverșed, forming salient portions, and appearing to advance towards the sea in the manner of a lava. It is thickest and most abundant at Monterone, where it rests on $_{i}$ r rock having all the characters of a transition formation.

The celebrated cascades of Tivoli are not due to escarpments of the compact limestone, forming the mass of these hills, but to a stoppage of the valley prodnced bydeposits from the waters which flow from it, and which were much more charged formerly than at present with carbonate of lime. The agitation of the waters gives rise to undulations in this deposit, not observable in the plain; and the less. abundant precipitation allows the limestone to acquire a texture and crystalline aspect, removing it from travertine and rendering it more like alabaster. The same facts, owing to the same causes, are observable at the beautiful cascades of Terni. Compact fresh-water limestone or travertine is first met with in the environs and lower parts; and afterwards at Rieti, at the confluence of the Velino and the Nera, this little river precipitates itself over a bar of crystalline concretionary limestone, formed in the same way and on the same fundamental compact limestone as at Tivoli. M. d'Halloy has observed fresh-water shells in the concretionary limestone.

H.T.D. B.

[To be continued,]

XXXII. Reply to Mr. Henderson's Remarks on Captain Sabine's Pendulum Observations. By Copt. E. Sabine, $R$. A. F.R.S. \&c.

\section{To the Editors of the Philosophical Magazine and Annals.}

Gentlemen,

$\mathrm{IN}$ reply to Mr. Henderson's communication in your last Number, I beg to acquaint him that a detailed account of the corrections of my pendulum experiments was presented to the Royal Society the day after my return from the continent, and read the same week, being in the commencement of last June *; and that I expect it will be printed at the close of a paper containing a continuation of the same experiments connecting Paris and London, in which I have been lately engaged.

Mr. Henderson has justly characterized the correction of the

* See our last Number, p: 143.-EDrr. 
length of the pendulum at New York as trifling: so also are the corrections at the four other stations, where the rate of the clock was obtained with the repeating circle. The observations recalculated show the slock to have been gaining at Jamaica $4^{s}, 07$ daily, instead of $4^{\mathrm{s}}, 14$; at Trinidad $3^{\mathrm{s}}, 23$ instead of $3^{\mathrm{s}}, 19$; at Maranham 2s,69 instead of $2^{\mathrm{s}, 70}$; and at Bahia $2^{\mathrm{s}}, 76$ instead of $2^{\mathrm{s}}, 68$. No correction amounts to onetenth of a second per diem, and the joint effect (in the comparison between the tropical stations and those of the middle and northern latitudes) does not exceed one hundredth of a second per diem; a quantity far too small to have any influence on the deductions.

I avail myself of the opportunity to subjoin a table of the corrected lengths of the pendulum, for the convenience of any person who may have occasion to employ them. The latitudes are given in the table to the nearest half minute, being sufficient for the required purpose. The observations of the southern stars have been recalculated with Mr. Fallows's right ascensions and declinations. The only alteration produced thereby worthy of notice is in the latitude of Ascension, from $7^{\circ} 55^{\prime} 48^{\prime \prime}$ to $7^{\circ} 55^{\prime} 10^{\prime \prime}$, by employing the more correct apparent declination of $\alpha$ Centauri: the alteration, however, has no influence beyond the mere correction; as $39.0152+0.20227$ $\sin ^{2} 7^{\circ} 55^{\prime} 48^{\prime \prime}$, and $39^{\circ} 0152+0.20227 \sin ^{2} 7^{\circ} 55^{\prime} 10^{\prime \prime}$ give the same theoretical pendulum for Ascension. In no other. instance do the corrections exceed a very few seconds.

\begin{tabular}{|c|c|c|}
\hline Stations. & Latitudes. & Pendulums. \\
\hline Spitzbergen & $79^{\circ} 50^{\prime} \mathrm{N}$ & $39 \cdot 21469$ \\
\hline Greenland . . . . & 74. $\quad 32 \cdot 5$ & $39 \cdot 20335$ \\
\hline Hammerfest . . . . & $70 \quad 40$ & $39 \cdot 19475$ \\
\hline Drontheim & 6326 & $39 \cdot 17456$ \\
\hline London $\ldots \ldots$ & 5131 & $39 \cdot 13929$ \\
\hline New York . . . . & $40 \quad 42 \cdot 5$ & $39 \cdot 10120$ \\
\hline Jamaica ...... & $17 \quad 56$ & $39 \cdot 03503$ \\
\hline Bahia & $12 \quad 59.5 \mathrm{~S}$. & $39 \cdot 02433$ \\
\hline Trinidad . . . . . & $1039 \mathrm{~N}$. & $39 \cdot 01888$ \\
\hline Sierra Leone . . . & $8 \quad 29 \cdot 5$ & $39 \cdot 01997$ \\
\hline Ascension . . . . & $7 \quad 55 \mathrm{~S}$. & $39 \cdot 024 \cdot 10$ \\
\hline Maranham .... & $2 \quad 31 \cdot 5 \mathrm{~S}$ & $39 \cdot 01213$ \\
\hline St. Thomas . & $\begin{array}{lll}0 & 24.5 \mathrm{~N}\end{array}$ & $39 \cdot 02074$ \\
\hline
\end{tabular}

London, Aug. 13, 1827.

Edward Sabine.

Nes Series. Vol. 2. No. 9. Sept. 1827. 2 A XXXIII. No- 